\title{
Si eres orejón, eres noble. Reflexiones en torno a las orejeras metálicas prehispánicas en el área centro-sur andina
}

\author{
If you are orejón, you are noble. Reflections on pre-Hispanic metal \\ earmuffs in the south-central andean area
}

\author{
Jédu A. Sagárnaga M. \\ https://orcid.org/oooo-0003-1500-2976 \\ Universidad Mayor de San Andrés \\ jasagarnaga@umsa.bo
}

\section{RESUMEN}

A partir de los datos etnohistóricos se pretende reconstruir cuál fue el uso de las orejeras en la sociedad inka, y su significado. Pero también se echa mano del dato iconográfico (plasmado en dibujos, vasos de madera y cuadros coloniales) y del dato arqueológico (recuperado especialmente en pequeñas figurinas metálicas).

La única evidencia del Período Pos Tiwanaku nos la proporciona la cultura mollo, aunque la muestra arqueológica se reduce a tan solo 4 orejeras de oro.

El análisis no se detiene allí sino que, en retrospectiva, procura observar lo que ocurría durante el Horizonte Medio, basando la observación tanto en la iconografía (representaciones en cerámica fundamentalmente) como en el objeto en sí mismo.

Palabras clave: orejones, inka, mollo, tiwanaku.

\section{ABSTRACT}

Starting from the ethnohistorical data, the aim is trying to reconstruct which was the use of earmuffs and their meaning in the Inka society. But it also makes use of the iconographic data (reflected in drawings, wooden vases and colonial paintings) as well as the archaeological data (recovered especially in small metal figurines). 
The only evidence of the Post Tiwanaku Period is provided by the Mollo culture, although the archaeological sample is reduced to just only 4 gold earmuffs.

The analysis does not stop there but, in retrospect, tries to observe what happened during the Middle Horizon, basing the observation both on the iconography (mainly ceramic representations) and also on the object itself.

Keywords: big ears, inka, mollo, tiwanaku.

ReCiBIDO: 20/07/2021 - AcEPTADO: 24/08/2021 - PublicADO: 25/11/2021

\section{INTRODUCCIÓN}

El uso de sendas orejeras está ampliamente documentado en los Andes septentrionales, desde Colombia hasta la costa central del Perú, e inclusive más hacia el Sur. Tanto la gente común como los arqueólogos no hemos podido sino quedar maravillados y fascinados con las grandes orejeras moche de oro con incrustaciones de piedras semipreciosas y que muestran un nivel artístico exquisito, todo lo cual ha sido recuperado en distintos contextos desde hace unos cuarenta años, aunque con anterioridad los coleccionistas y museos poseían piezas de esas características. No menos ostentosas son varias orejeras wari, chimú, etc.

No sucede lo mismo en el área centro-sur andina, donde las colecciones no son tan cuantiosas, y la investigación es todavía exigua. Aún con esas insuficiencias, es deber nuestro dar a conocer el estado de la cuestión.

El presente artículo forma parte de un corpus mayor que vengo desarrollando desde hace más de veinticinco años cuando defendí mi tesis de Licenciatura en Arqueología referida a la metalistería suntuaria precolombina centro-sur andina. No a pasos agigantados, como lo hubiera deseado, pero creo que hoy conocemos más que hace un cuarto de siglo sobre el tema, y por eso se hace necesaria la revisión y consecuente actualización de datos que permita el avance del conocimiento.

Hay, en el ser humano, la necesidad del adorno y el espacio privilegiado es, sin duda, el propio cuerpo. Antonio Esquivias ha dicho que "El ser humano tiene una necesidad en lo más profundo de expresarse y uno de esos modos de expresión es el adorno... sólo el espíritu es capaz de descubrir la belleza, y el adorno está relacionado con la belleza de las cosas... El adorno es por tanto algo estrictamente humano y que humaniza, porque el ser humano es el único ser con cuerpo que vive un mundo de significados... El adorno surge de una profunda necesidad del ser humano de encontrar el significado de belleza de lo material" (Esquivias, 2014). Pero si, en el afán interpretativo, nos quedáramos en la percepción del artefacto como mero adorno, a no dudarlo que solo una ínfima parte habría quedado resuelta. El artefacto metálico, en este caso, es mucho más que un simple adorno. 
Con acierto, también, ha señalado María Esther Prados que "El ser humano desde tiempos ancestrales ha utilizado una serie de elementos y objetos (collares, pulseras, pendientes, anillos, pinturas, tatuajes, perfumes...) para adornar y realzar el cuerpo... se utilizan estos elementos como señas de identidad, de pertenencia a un grupo social, y en otras ocasiones el uso de estos elementos forma parte esencial del proceso de determinados rituales. Con todo ello queremos destacar la necesidad de expresión del ser humano. Cuando la persona quiere expresar un estado de ánimo, un sentimiento, un pensamiento, una emoción..., el cuerpo es el vehículo. Muchas son las formas de presentar el cuerpo al resto de la sociedad cuando queremos comunicarnos... hay espacios y ocasiones en los que el ser humano necesita... expresar, no a través de la palabra, sino a través de lo que lleva puesto..."

“... Como última función atribuida al uso de complementos y accesorios, apuntábamos... la identificación que se establece entre el objeto y la personalidad... [de quien] lo lleva puesto. En ese sentido, algunos de los actos que se realizan en el cuerpo puede[n] llevarse a cabo por cuestión de moda, pero terminan convirtiéndose en rasgos de identidad de la propia persona" (2002, pp. 242-243).

En suma, el cuerpo se torna en una geografía susceptible de alterarse, a través de elementos incorporados. Pero no son simples adornos, son señales, comunican, expresan. Se tornan en distintivos étnicos, símbolos de poder, etc. Significantes que solo encuentran significado dentro del grupo. Pero no hay significantes sin significado, y cuando una cultura fenece y no deja testimonio escrito, hallarlo es tarea difícil, casi imposible. Por ello, en la arqueología andina nos enfrentamos a grandes retos y tratamos de escudriñar con la escasa evidencia disponible. Sucede ello, también, en el estudio de los artefactos metálicos y, concretamente, en el caso de las orejeras.

En ese marco, los artefactos metálicos juegan un papel similar al descrito, pero con la añadidura de que, en la época prehispánica, los metales encerraban un gran significado simbólico/religioso con implicancia en el estatus social. En la presente entrega pretendemos establecer algunas propuestas teóricas en torno a la orejera metálica.

\section{ANTECEDENTES HISTÓRICO-CULTURALES EN TORNO A LOS ADOR- NOS PARA LAS OREJAS}

En otra parte nos hemos ocupado del tema (1986 h y 1986 i, 1995). Acá ampliamos la información y el análisis

Después de la invasión a los Andes, los españoles comenzaron a llamar "orejones" a los miembros de la nobleza inka debido a que estos tenían por costumbre hora- 
darse y dilatarse los lóbulos de la oreja en forma exagerada, para colocar en ellos enormes orejeras. Pedro Pizarro (1571) describe:

"Sajaban la carne de la oreja cada dia para que les fuese creciendo. Auia algunos que las tenian tan grandes, que les llegauan hasta los hombros, y el que mayores las tenia hera mas gentilhombre entrellos". Y Garcilaso de la Vega nos dice que tres cosas caracterizaban principalmente al Inka: el uso del llauto ${ }^{1}$, el cabello bien corto y el uso de sendas orejeras (figura 4) colocadas en los lóbulos horadados y dilatados tan exageradamente que el cronista no puede ocultar su admiración cuando dice que "parece imposible que tan poca carne como la que hay debajo de la oreja venga a crecer tanto". Por ello "les llamaron Orejones los españoles", agrega (Libro 1ํㅡㄹ cap. XXII, p. 61).

Pero no solo son Pedro Pizarro y el cronista inca quienes mencionan a los orejones; lo hacen todos, o casi todos a su vez (al menos pude comprobarlo en Sancho de la Hoz, Juan Diez de Betanzos, Pedro Cieza de León, Agustín de Zárate, Cristóbal de Molina (el Chileno), Diego de Trujillo, Juan Polo de Ondegardo, Sarmiento de Gamboa, Cabello de Balboa, Joseph de Acosta, Martín de Morúa, Guamán Poma, Antonio de la Calancha y Bernabé Cobo), pues hasta el siglo XVII la presencia de los orejones debió ser habitual, especialmente en la región del Cuzco.

Bernabé Cobo (1653) explica: "nuestros españoles [les] llaman Orejones, porque traían las orejas horadadas de extraña grandeza"; y Cristóbal de Molina (1553) (El chileno) complementa:

"llámanse orejones, porque traen los orejas horadadas y meten dentro de ellas unas ruedas hechas de juncos anchos con que acrecientan las orejas, y cada una de ellas, puesta la rosca de junco dentro, la hacen tan ancha como una gran rosca de naranja. Los señores y principales traían aquellas roscas de oro fino en las orejas".

Cobo (1653) añade:

"solo se diferenciaba el rey en tener más grandes los horados de las orejas y mayores y más ricos zarcillos; en andar trasquilado con no más de uno o dos dedos de cabello, y en que su llauto era de muchos colores y los de los otros del linaje de los Incas de uno solo".

La perforación se iba ampliando con el paso del tiempo y la persona tenía derecho a llevar orejeras cuya dimensión era proporcional a su rango. Si por casualidad el lóbulo se rompía, se tomaba el hecho como de mal presagio y la persona no era elegible para ciertos cargos administrativos (Guamán Poma, 1980, T. I, p. 66; T. III: 1132; Baudin, 1962, pp. 123-24). 
A propósito, conviene mencionar que Atawallpa perdió una "oreja" en la batalla de Tumipampa el 23 de mayo de 1529, derrotado por el ejército huascarista al mando del general Atocc. Por orden de Huáscar fue sometido al oprobioso castigo incaico de cortarle una "oreja" para que nunca llegue a ser "Orejón" y menos Sapa Inka. Un defecto físico era impedimento mortal para ceñirse la Mascaipacha, símbolo de poder imperial, impuesta por el Sapa Inka cesante. Desde entonces se cubría con una manta la cicatriz. Ya sin una oreja se fugó de la prisión con ayuda de su Padre el Sol, convertido en un Amaru (serpiente sagrada) (Blogspot de Apolinario Mayta: https://apolinariomayta.com/la-oreja-de-atahualpa/).

Parece ser que Mayta entresacó el dato de Pedro Pizarro (1571), quien señala:

"Poniase este señor [Atawallpa] la manta por encima de la caueza y atauasela deuaxo de la barua, tapandose las orexas: esto traya el por tapar una orexa que tenia rronpida, que quando le prendieron los de Guascar se la quebraron".

El resto del relato puede ser una conjetura de Mayta. El hecho es que, si el dato es cierto, el mal augurio se cumplió y Atawallpa nunca llegó a ponerse las orejeras reales, pues antes cayó prisionero de los españoles, lo cual significó la caída del modelo socio-político que afectó a todo el Mundo Andino.

El dato etnográfico demuestra que los lóbulos de las orejas pueden ser ensanchadas paulatinamente, hasta proporciones bastante grandes. Hoy en día muchos jóvenes, en la misma ciudad de La Paz, recurren a esta práctica con fines estéticos (y tal vez identitarios), lo cual nos permite observar el proceso. Es importante subrayar que no se trata de un continuum cultural, sino de influencias foráneas contemporáneas. Uno de ellos aceptó posar para nosotros (figura 1).

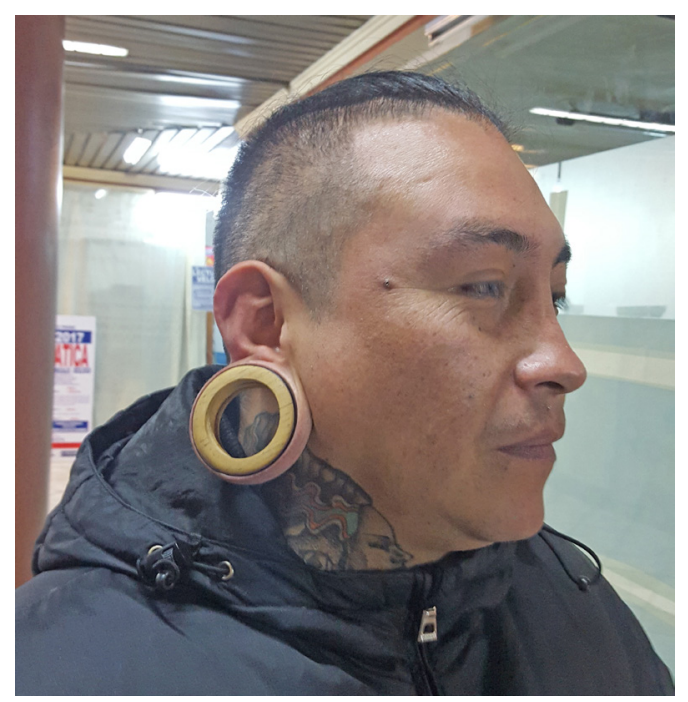

Figura 1. Joven luciendo grandes orejeras en pleno centro paceño (Foto JASM 2019). 
Me han interesado, particularmente, algunas menciones acerca de estos adornos. Por ejemplo, Guamán Poma nos dice que los miembros de la nobleza usaban orejeras pero que no por ello eran todos Qhapac apu (rey), ya que éste era único. Los inkas perforaban los lóbulos de las orejas a los jóvenes pertenecientes a los linajes reales en su iniciación. Para tal fin se realizaban especiales ceremonias durante el mes de noviembre (Guamán Poma, 1980, p. 231).

De la información gráfica del cronista indígena, se desprenden varias cosas. Una de ellas era que el Qhapac apu o Sapa Inka (el soberano) era el principal orejón (que además usaba las orejeras más grandes); y que la clase noble era "orejona" de nacimiento. Cobo (1653) les llama "orejones de la sangre real”. V.g.,Guamán Poma retrata a todos los soberanos siempre con orejeras, y al Inca Roca con su hijo (todavía niño); ambos portando sendas orejeras (véase figura 2). Pero también es importante el dato de que los jóvenes podían convertirse en orejones, lo que para algunos cronistas equivalía a ser "caballeros".

Acosta (1653), v.g., dice que:

"orejones... eran como caballeros de linaje antiguo" (1590). Dos frases de Cobo también son ilustrativas al respecto: "...cuando los mancebos se hacían orejones y armaban caballeros...", “...se armaban orejones o caballeros...”.

Por su parte Molina (1553) señala que "había dos maneras de orejones". La primera sería por nacimiento, y la segunda por mérito.

Se dice que la gente reunía a sus hijos a los diez años, les vestían apropiadamente, les colocaban unas sandalias de paja y ayunaban al estilo andino (si vale el término) que era "no comer sal ni ají ni beber chicha". Además, debían ir durante algunos días
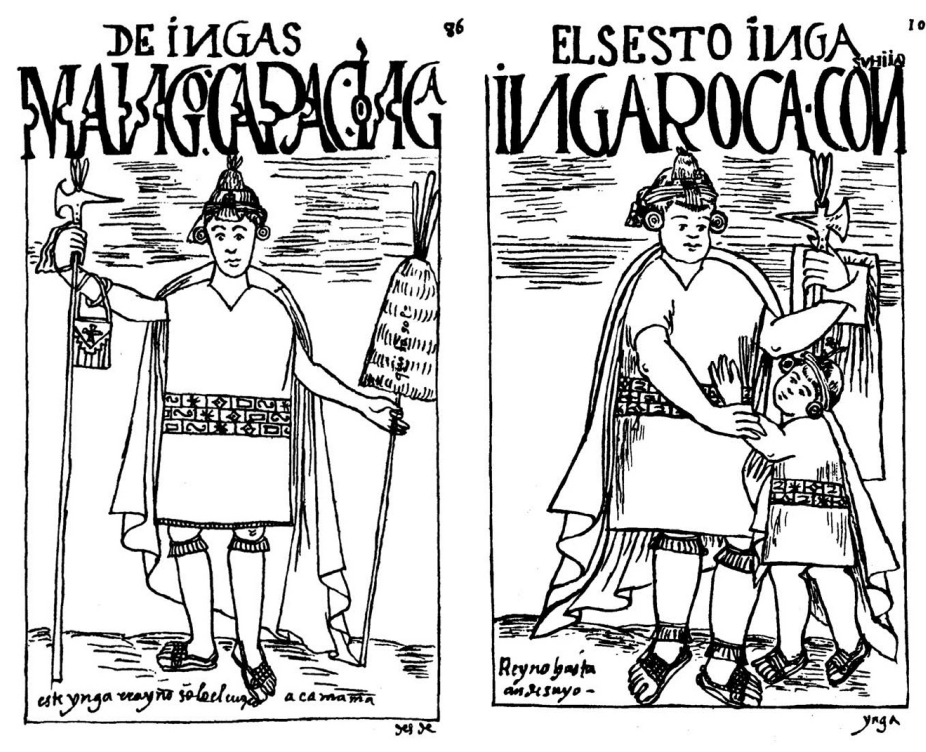

Figura 2. Izq.: Guamán Poma representa siempre a todos los Sapa inkas con grandes orejeras. Der.: Inka Roca con su hijo. Ambos portan sendas orejeras (Fuente: Guamán Poma). 
a un cerro cercano al Cuzco (Guanacaure), donde adoraban a un ídolo, y el que más se esmeraba en ello, era más reconocido. Se dice que ello duraba un mes, al cabo del cual, en el mismo Guanacaure:

"les horadaban las orejas y les ponían bragueros; metíanles a las orejas unos palitos delgados, y cada día un poco más grueso, hasta que se venían a poner una rodaja grande como aro de cedazo redonda, de unos juncos que en esta tierra se criaban, anchos, muy livianos: rajábase la carne de las orejas cada día para que les fuese creciendo y dando de sí: había algunos que las tenían tan grandes que les llegaban hasta los hombros; el que mayores las tenía era más gentil hombre entre ellos. Después de haberles horadado las orejas a estos mozos, hacían grandes bailes en la plaza" (Pizarro, 1571).

Cobo (1653) complementa señalando que: "todos los que se hacían orejones en la fiesta del Raymi... [eran] mancebos que se armaban orejones" y Acosta (1590) añade que:

"En estas fiestas se dedicaban los muchachos Ingas, y les ponían las guaras o pañetes y les horadaban las orejas y les azotaban con hondas los viejos y untaban con sangre el rostro, todo en señal que habían de ser caballeros leales del Inga".

A la larga, estos nuevos orejones, eran los que dirigían las huestes del inka, los más valerosos guerreros, "los orejones... eran el nervio del ejército" (Cobo, 1653).

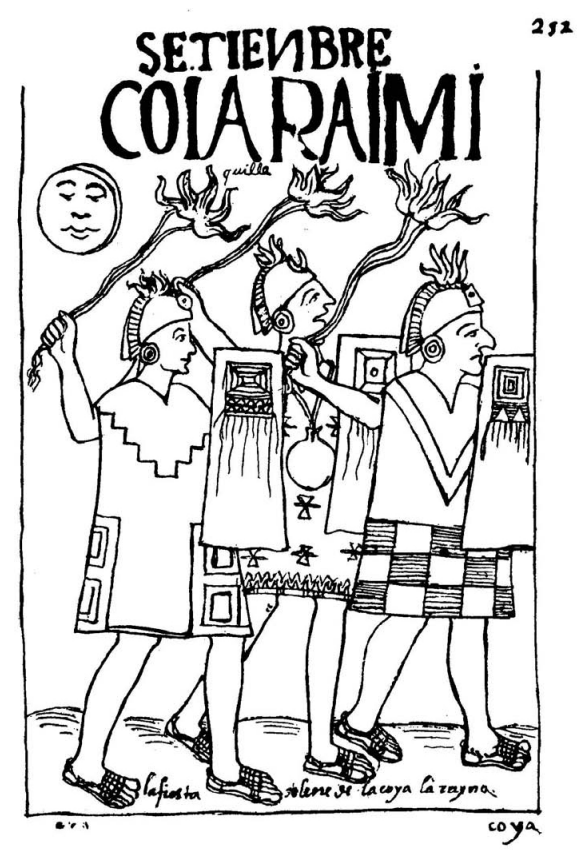

Figura 3. Los guerreros más valerosos eran ungidos orejones (caballeros) (Fuente: Guamán Poma). 


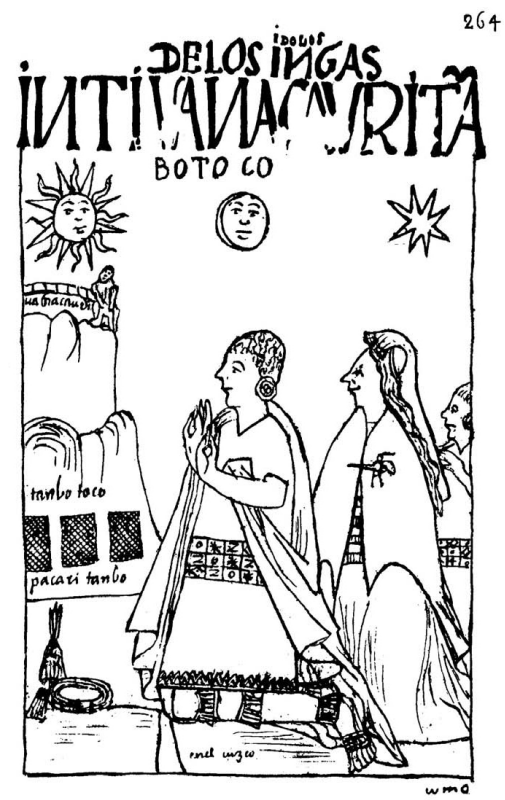

Figura 4. El Inka usa orejeras y el cabello corto. Su esposa no lleva orejeras, en cambio, sí, el tupu o prendedor de su manta (Fuente: Guamán Poma).

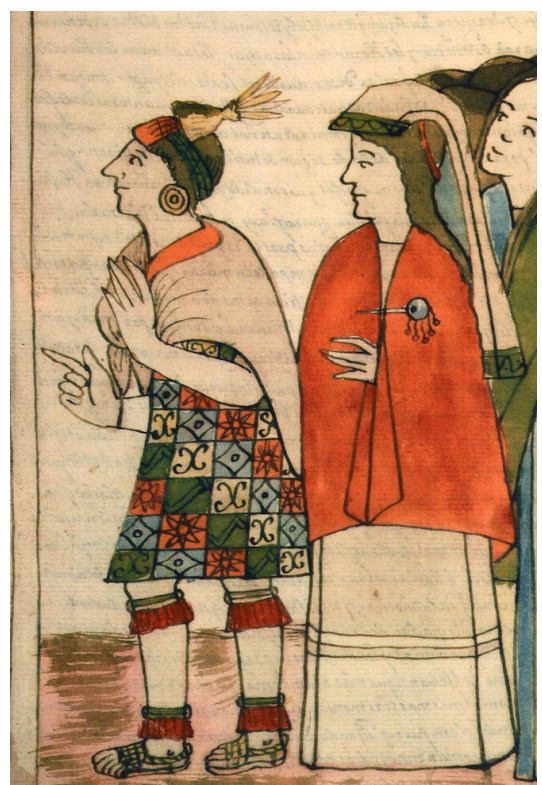

Figura 5. El Sapa Inka, ataviado con orejeras y su esposa, la Koya, con un tupu sujetando la manta (Fuente: Martín de Murúa)
Otro interesante dato señala que:

"Mango Inga... hizo una fiesta muy principal, en la qual se horadaban las orejas, y en esta fiesta nosotros los ingas solemos hacer la mayor fiesta que hacemos en todo el año, porque entonces nos dan mucho nombre y nuevo nombre del que teníamos antes..." (Titu Cusi cit. por Medinaceli, 1995, p. 32).

Otro aspecto, que se evidencia de muchas de las ilustraciones de la "Primer Nueva Coronica", es que las orejeras eran adorno masculino. Dicho sea de paso, en las representaciones antropomorfas en cerámica modelada tiwanaku que se conocen, las mujeres no llevan orejeras siendo, aparentemente, un atributo exclusivamente masculino desde esa época. También resalta el hecho, en todos los dibujos de Guamán Poma, de que los orejones tengan el cabello muy corto, casi rapado (véase figura 4). Ya Pedro Pizarro notó tal cosa cuando dijo que:

"todos estos señores andaban tresquilados y los orejones como a sobre peine".

Pero la información etnohistórica sugiere que no todos los orejones usaban el cabello corto. Así Molina (1553) señala:

"los unos de estos orejones eran trasquilados y los otros de cabellos largos, que se llaman hoy día chilques; estos pelearon los unos con los otros, y los trasquilados subjectaron a los otros, en tal manera que jamás alzaron cabeza ni habitaron por vecinos de la ciudad del Cuzco; y así hay hoy día pueblos dellos por las comarcas de la tierra del Cuzco; mas, en la propia ciudad no los consintieron más vivir sino solamente la gente común dellos para servir en lo que les mandasen".

El pueblo podía obtener el derecho de usar orejeras pero con la limitación en el tamaño del horadado del lóbulo que no podía pasar de la mitad del que tenía el Inka, además de usar orejeras de ma- 
teriales ordinarios que diferenciasen a las diversas naciones tales como la madera, lana, totora, etc. (Garcilaso Libro 1², cap. XXIII, p. 62; Baudin 1964, p. 135). Lothrop menciona el uso de "carretes" que variaban de tipo en cada provincia indicando además que la nobleza usaba enormes carretes de metal precioso (1964, p. 42).

En las descripciones que se hacen del soberano Inka, invariablemente se mencionan las grandes orejeras (véase por ejemplo Baudin, 1962, p. 114), y de la misma forma los artistas andinos de la Colonia (caso de los artesanos fabricantes de vasos de madera [véase figura 6], y los retratistas [véase figura 7], además de Murúa y del ya mencionado Guamán Poma) no dejaron de representar a los inkas con sus grandes orejeras (véase la descripción de un keru en Posnansky, 1957, p. 69). Este mismo autor (Posnansky, 1957, Pl. CLV. B.), en su reconstrucción hipotética del rostro de Atawallpa, no pudo menos que incluir las respectivas orejeras. Por ello nos sorprende que tanto Diego Rodríguez de Figueroa al describir al Inka Titu Cusi Yupanki en 1565 (cit. por Bingham, 1972, p. 70) y Arzans de Orzua y Vela al describir al Inka Atawallpa -aunque ya en el s. XVIII y, por tanto, de oídas (cit. por Gisbert 1980, p. 121) - no hubiesen mencionado sus orejeras; hecho que sólo puede atribuirse a una grave omisión porque, como acabamos de ver, el propio Titu Cusi habla de la importancia que para ellos [los inka] tenía la orejera. Aunque, como hemos visto en un párrafo anterior, tal parece que Atawallpa perdió una oreja a manos de los huascaristas, lo que le impidió portar las anheladas orejeras.

Además de la evidencia iconográfica, contamos con importante evidencia arqueológica. De hecho, casi todas las figurillas masculinas elaboradas en metal por los inkas (figuras 8 y 9), ahora lo sabemos, representan "orejones".

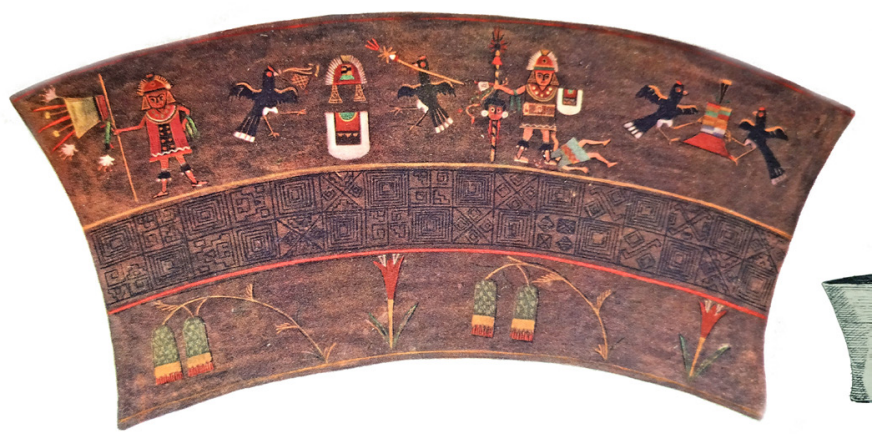

Figura 6. A guisa de ejemplo se muestra este keru de madera, en el que se ve un guerrero inka pisando el cuerpo de un personaje cuya cabeza ha sido cercenada y cuelga de la vara que el guerrero sostiene con una mano. Dicha cabeza muestra sendas orejeras, por lo que se puede suponer que el guerrero es un capitán de Atawallpa quien ha victimado a su hermano Waskar (Fuente: Posnansky, 1957, Plancha XLV a). 


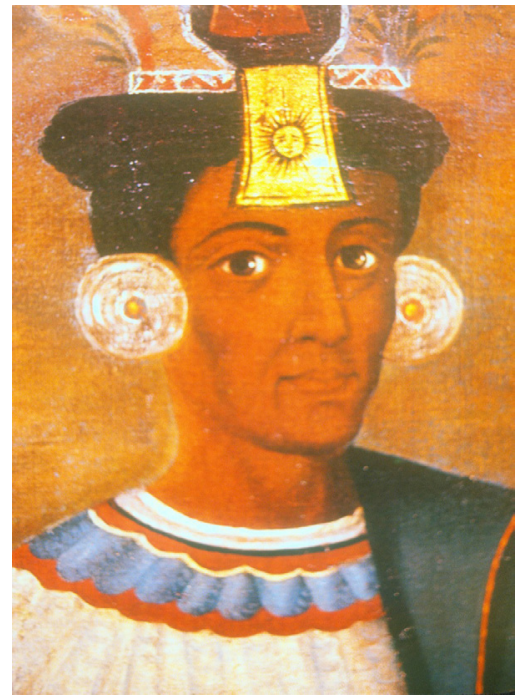

Figura 7. Retrato del Inka Lloq'e Yupanki portando diadema de oro y orejeras menos relucientes (tal vez de plata). Colección Particular / La Paz. (Fuente: De Rojas, 2008, p. 63).

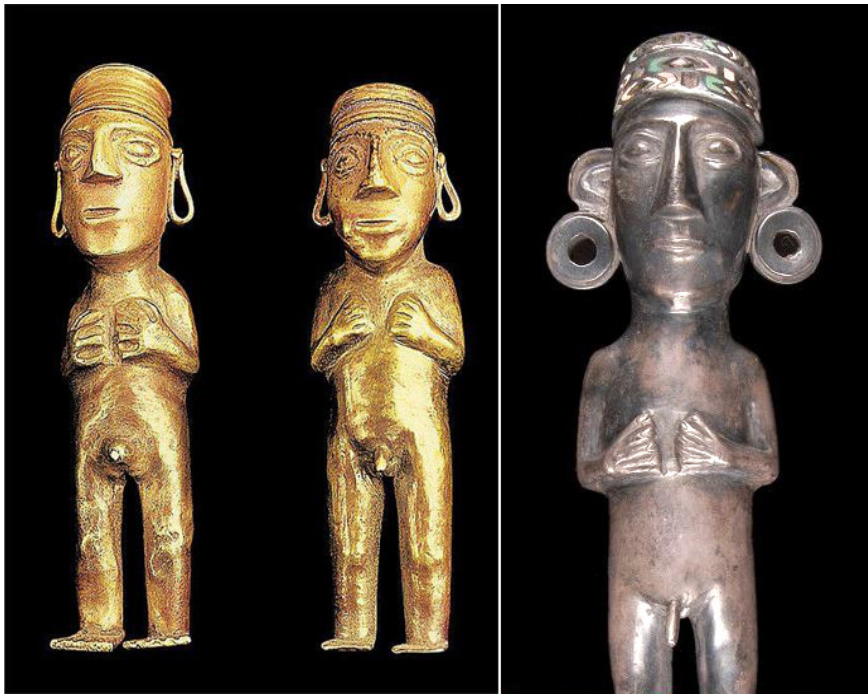

Figura 8. Izq.: Dos pequeñas figurillas inka de oro que muestran personajes masculinos con los lóbulos de las orejas perforados y dilatados (Fuente: https://www. pinterest.de/pin/455215474812004933/).

Der.: Una pequeña figurilla de plata $(20,1 \mathrm{~cm}$ de alto) mostrando un personaje con sendas orejeras (Fuente: Museo Quai Branly, $N^{\circ}$ de inv. 71.1887.114.90)

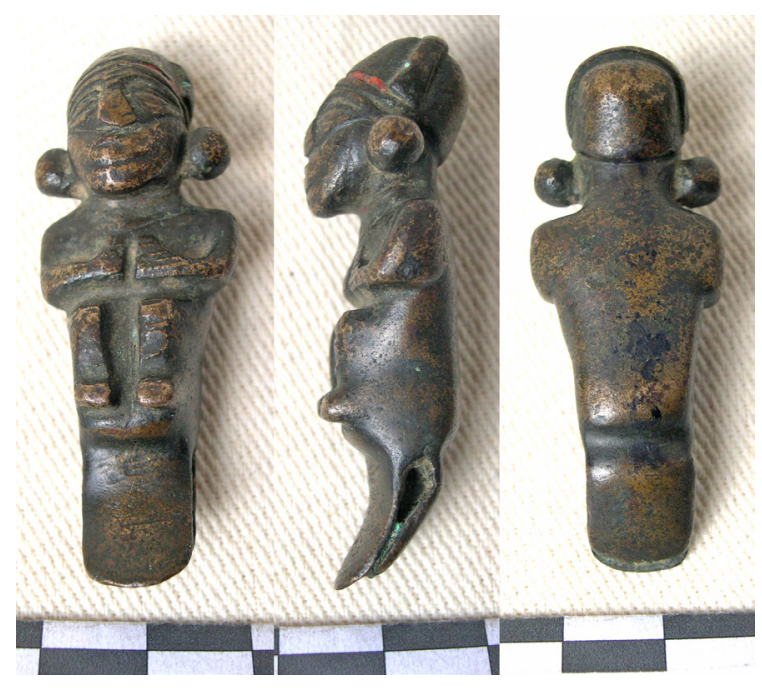

Figura 9. Magnífica miniatura de metal (posiblemente bronce) de la CFBLP (Cod CFBLP 02707). Representa al Sapa Inka sedente, con su chucu (casco), a un lado el llautu y sendas orejeras casi esféricas. Conserva un poco de pintura roja en el borde del casco. Por ss pequeñas dimensiones y la forma de su base, parece haber servido como remate de un bastón (Fotos Archivo MMPP). 
Figuran en nuestras colecciones, orejeras en forma de poleas. Se introducían a través del hueco practicado en el lóbulo de la oreja. Han debido ser las más comunes, incluso, antes de la dominación inka. Por ello, y toda vez que de casi todas las que conocemos se desconoce el contexto de las que fueron recuperadas, es difícil establecer su filiación cultural.

En el MMPP de la ciudad de La Paz, existen varias orejeras del tipo "polea". En el registro que poseemos figuran, al menos, los especímenes codificados como CFBLP 01739, 1740, 01741, 01742, 01743 y 1744; y MDO (MMPP) 00893, 00894, 00895, 00896, 01341, 01343, 01344, 01434 y 01435 (Al menos dos de ellas proceden de la CVM). De las piezas pertenecientes a la CFBLP, las 4 primeras tienen como lugar de procedencia el ambiguo dato "Zona del lago Titikaka"; sólo la última (CFBLP 01744) procedería de “Tiwanaku” (figura 10).

También en la colección MBG (hoy en el MUSEF) se tienen 4 orejeras de oro del tipo "polea" (códigos MBG 27208, 27209, 27455 y 27457) (figuras 11).

Aparte de estas 4 piezas, el MUSEF tendría otras dos orejeras de oro (figura 12).

Dicho sea de paso, la técnica de elaboración era el martillado y recortado de dos círculos unidos por un tubo en la parte central. Pero como muchas veces debieron desoldarse, y el usuario de seguro no sabía cómo repararlas, entonces martillaba ambos discos y los convertía en lentejuelas. En el MMPP existen 4 piezas que muestran esto (CFBLP 01709, 01717, 01725 y 01726). Incluso una de ellas, presenta un orificio casi en el borde, practicado para darle, quizás, un uso diferente (figura 13).

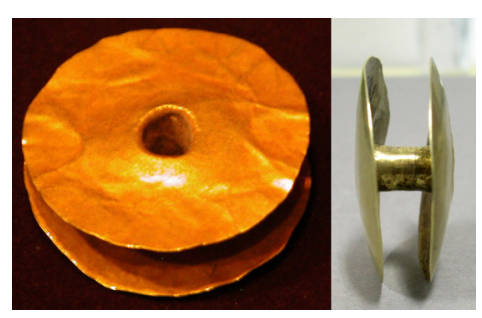

Figura 10. Orejeras como estas se exhiben en el MMPP (Fotos JASM y Archivo MMPP).

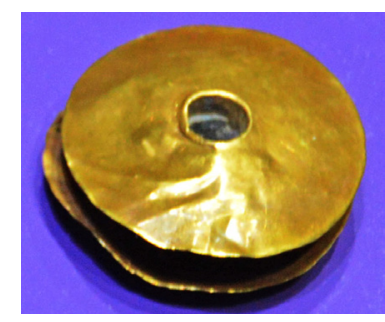

Figura 11. Una de las orejeras de la colección MBG en el MUSEF (Foto JASM).
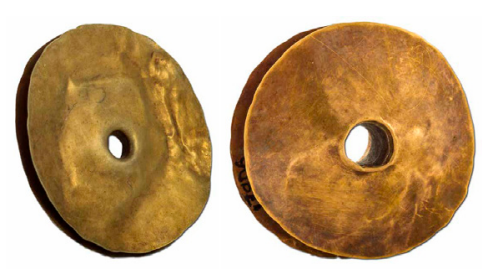

Figura 12. Dos orejeras del MUSEF (Códigos 10306 y 17906) (Fuente: Fernández, 2016, $p$. 128, 131). 


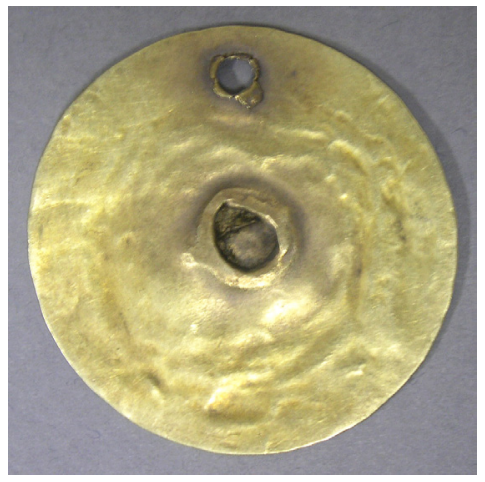

Figura 13. Orejeras como estas se exhiben en el MMPP (Fotos JASM y Archivo MMPP).

\section{OREJERAS PREINKAS}

Tan singular costumbre, sin embargo, los inka la habrían heredado de las sociedades precedentes. Ya Baudin hace notar que la costumbre andina de llevar enormes aretes era pre-inka (1964, p.124). De hecho, los moche y los chimú (en la costa norte del Perú) fueron quienes utilizaron los ornamentos para la oreja más exagerados del Mundo Andino, tanto en peso como en tamaño. Aunque el tema escapa del marco geográfico señalado en el título de esta entrega, remito al lector interesado a observar las grandes orejeras recuperadas por los arqueólogos en la estructura piramidal de Sipán, y que se exhiben en el Museo "Tumbas Reales" de la ciudad de Lambayeque (Perú).

Para el área que nos interesa, tenemos clara evidencia del uso de este adorno entre los mollo y, anteriormente, entre los tiwanaku. En el caso de los mollo, se conocen algunas orejeras excavadas en un cementerio atribuido a esa cultura de los valles mesotermos de Consata. Fue José Huidobro quien en 1978 excavó 4 orejeras de oro (figura 14) en la tumba № 8, en la necrópolis mollo de Palla Palla (el Choro) del tipo que hemos llamado "polea" (Huidobro, s/f), demostrando su vigencia en el período pos Tiwanaku. Vale la pena mencionar que los 4 especímenes corresponden evidentemente a 2 pares, dado que sus diámetros son de $4.2 \mathrm{~cm}$ para dos de ellos y de $3.1 \mathrm{~cm}$. para los otros dos (Huidobro, 1984, p. 152).

En cuanto al Horizonte Medio, la información es más cuantiosa. De Tiwanaku poseemos ceramios antropomorfos, donde el individuo retratado muestra sendas orejeras. Uno de ellos (figura 15), realmente soberbio, es el que publica Posnansky en 1957. Se hallaba en poder de una familia particular en La Paz, y se desconoce su actual paradero.

Durante nuestra intervención arqueológica en la isla de Pariti entre 2004 y 2005, pudimos recuperar varias piezas cerámicas antropomorfas, que confirman la im- 
portancia de las orejeras entre los miembros de sexo masculino en la sociedad tiwanaku. Acá se muestran algunos ejemplares (figuras 16-19):

La evidencia iconográfica sugiere que incluso sus animales regalones (los monos concretamente) también eran "regalados" con orejeras (figura 20).

Pero allí no acaba la valiosa información recuperada en nuestras excavaciones. Entre los hallazgos se tiene una magnífica pieza que representa a un señor que lleva un turbante en su cabeza, y las orejeras que porta no son del tipo "polea" ya conocido sino que, se puede apreciar con claridad, lleva una espiga adherida al cuerpo principal de la orejera y que atraviesa el lóbulo hacia atrás. Conocemos bien ese tipo, y sabemos que era de uso corriente sobre todo entre los moche. Lo interesante es que, por vez primera, se observa en la iconografía tiwanaku (figuras 21 y 22).

Tenemos indicios de que este tipo de orejera también pudo haber sido utilizado en el área circum lacustre. De hecho, existe una pieza en el MUNARQ que yo interpreto como orejera, y que posee la forma anotada (figura 23).

También en Arica se reportó un par de piezas que podrían corresponder a este tipo (Cifuentes 2014) (figura 26).

Y a propósito del Norte Grande de Chile, en San Pedro de Atacama (espacio que se hallaba dentro de la esfera de interacción de Tiwanaku), también se posee información pertinente. Ariadna Cifuentes (2014) ha revisado valiosa información respecto a las orejeras. Las piezas por ella estudiadas "corresponden a discos con un agujero central y una depresión interior circundando este agujero. Estos serían una especie de pendiente colocados en el interior del lóbulo de la oreja (Figueroa, 2012), por lo que no corresponderían a los pendientes típicos del área Diaguita. En el IIAM (Cifuentes, 2014) se ha registrado un particular disco de cobre (PMPC 86) procedente de Solor-3, tumba 940, que reúne estas características, presentando el formato de una orejera (Horta com. pers., 2013)" (véase figuras 24-25).

Cifuentes continúa diciendo: "Si bien se ha asumido para las orejeras una cronología tardía, el contexto con alfarería Negra Pulida -"una botella sin cara pero con orejas"-, del cual procede la pieza, indica su adscripción a la fase Quitor. Asimismo, es posible asegurar su función como pendientes, ya que Le Paige en sus notas inéditas relata: "con aros de cobre y cuenca en sitio (orejas)". Por otra parte, una fotografía publicada por Le Paige (1964, p. 208) muestra una orejera in situ en un cráneo de Solor-3, la que es descrita como "Solor-3. Aros in situ, hechos de cobre con cuentas de turquesa al centro” (Cifuentes, 2014) (figura 26).

Sus reflexiones finales son de mucho interés. Ella dice: "Distribución. Se ha supuesto que estas piezas corresponden a objetos del período Tardío, constituyendo adornos reservados para la nobleza incaica (Horta 2010). No obstante, en Pampa Alto Ramírez (Az-122), al interior de un gorro polícromo Tiwanaku de cuatro puntas, se encontraron un par de orejeras las que son descritas como "dos objetos si- 


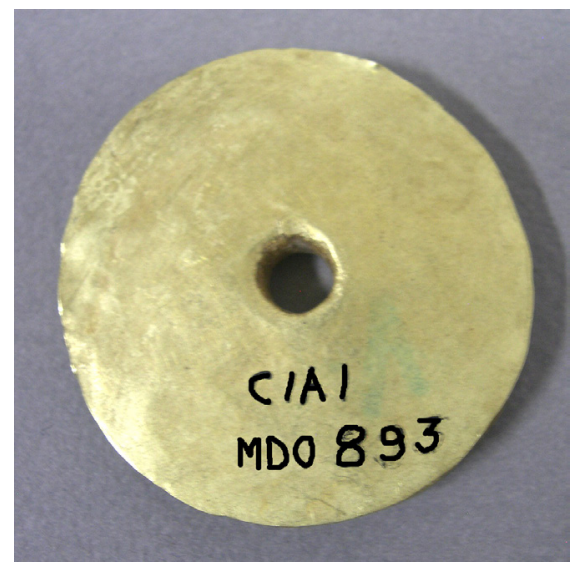

Figura 14. Una de las cuatro orejeras mollo, hoy en el MMPP (Codificadas como MDO 893, 894, 895 y 896) (Foto Archivo MMPP)

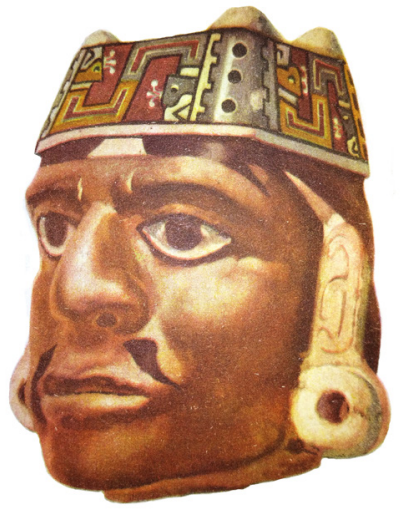

Figura 15. Personaje usando un gorro de cuatro puntas $y$ orejeras (Fuente: Posnansky, 1957, Plancha LXVI G).

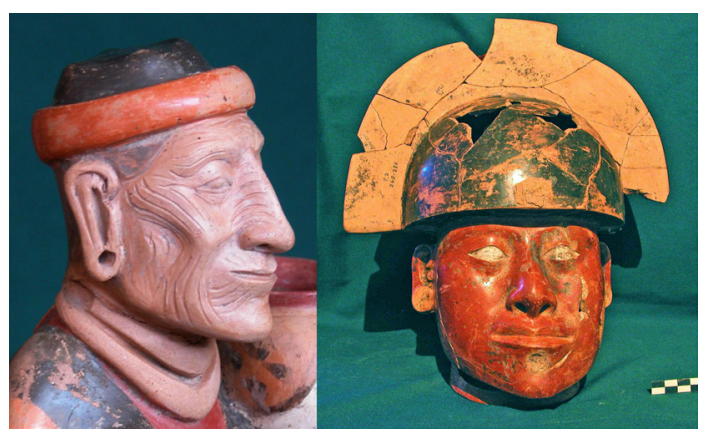

Figura 16. Ceramios de Pariti (Códigos PRTLP 00072 y 00188) (Fotos JASM).

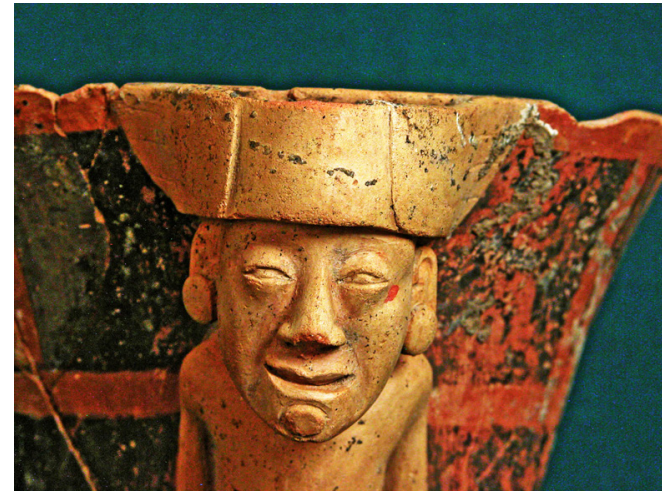

Figura 17. Ceramio de Pariti que muestra, tal vez, a un sacerdote que porta diadema, tembetá y orejeras (Código PRTLP 00086) (Foto JASM).

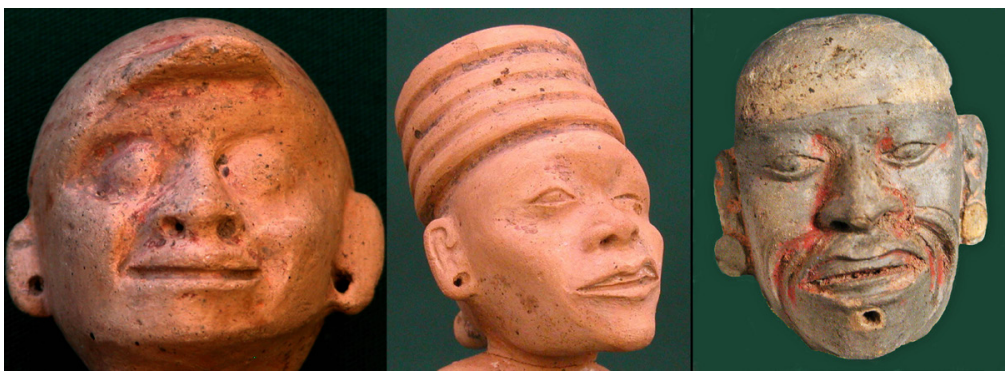

Figura 18. Pequeños ceramios de Pariti que muestran tanto la horadación como el uso de orejeras (Códigos PRTLP 00028, $00175 y$ 00176) (Fotos JASM). 


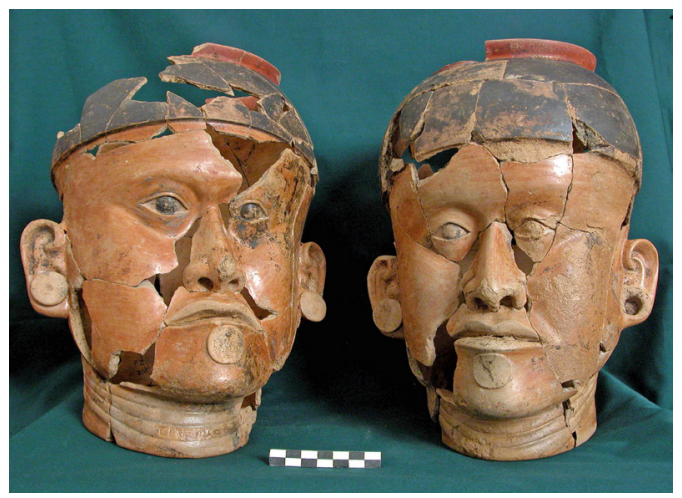

Figura 19. Par de vasijas cerámicas antropomorfas de Pariti, donde los personajes usan tembetá y orejeras (Códigos PRTLP 00316 y 00317) (Foto JASM).

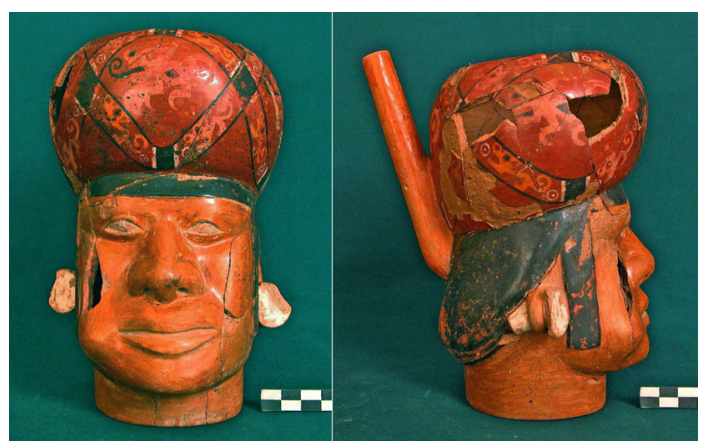

Figura 21. Vista frontal y lateral del ceramio de Pariti que lleva el código PRTLP 00071 (Foto JASM).

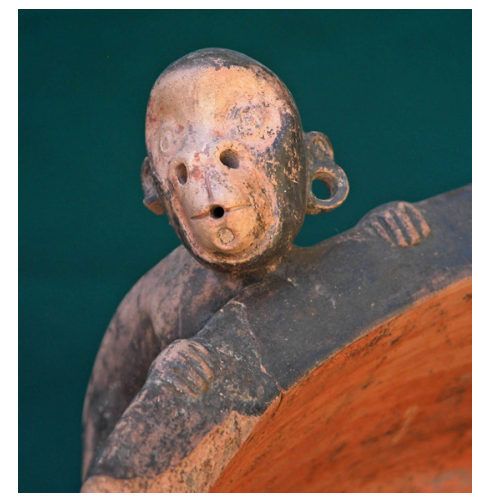

Figura 20. Magnifica pieza cerámica proveniente de Pariti que muestra a un mono silvador con tembetá $y$ sendas orejeras (Código PRTLP 00186) (Foto JASM).

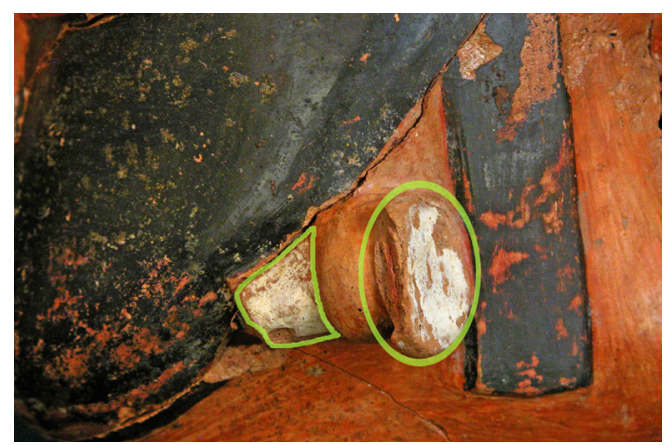

Figura 22. Detalle de la anterior pieza en el que se han resaltado las partes de la orejera (Foto JASM).

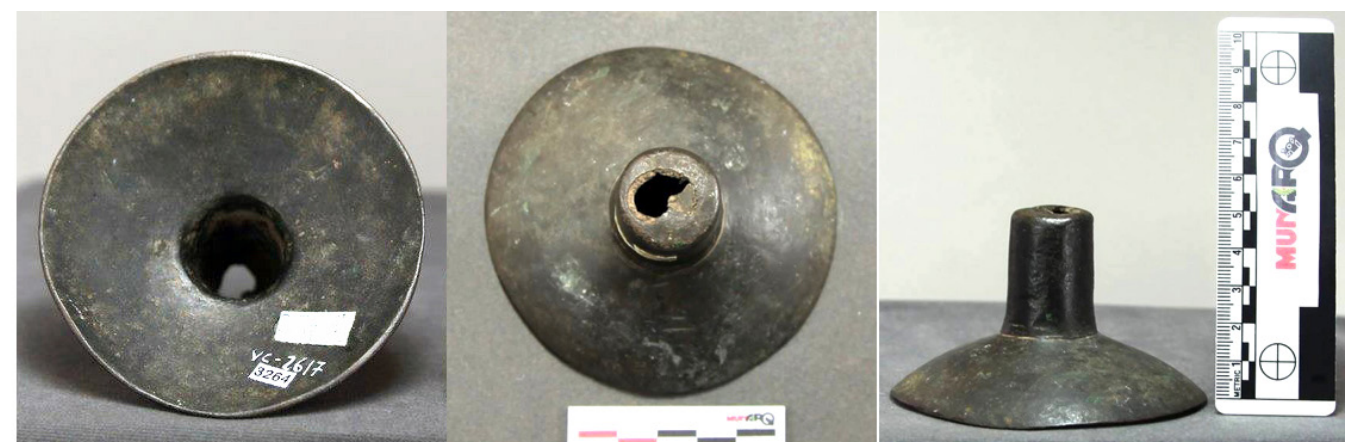

Figura 23. Orejera metálica de la CFDLP. Lleva el código 3264 (Fuente: MUNARQ). 

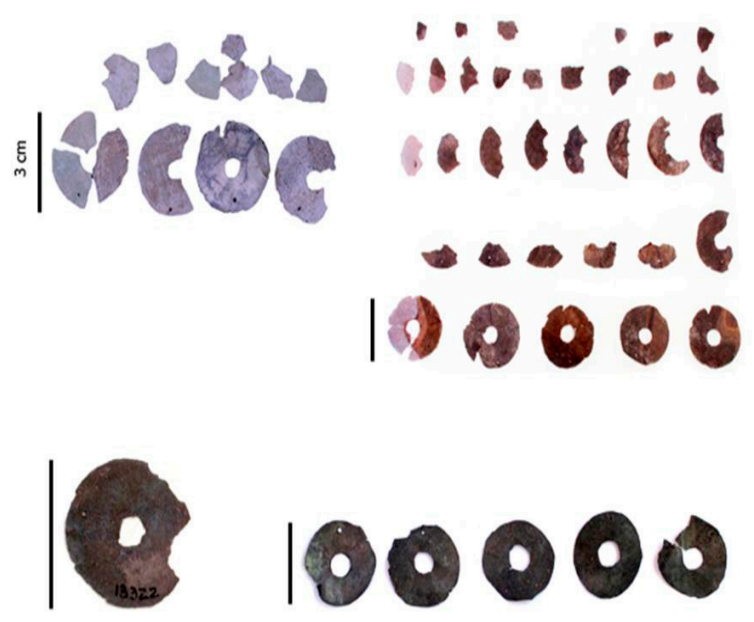

Figura 24. Discos de plata procedentes de distintas tumbas de Coyo Oriente, Coyo-3 y Tchilimoya (Fuente: Cifuentes, 2014).

a)

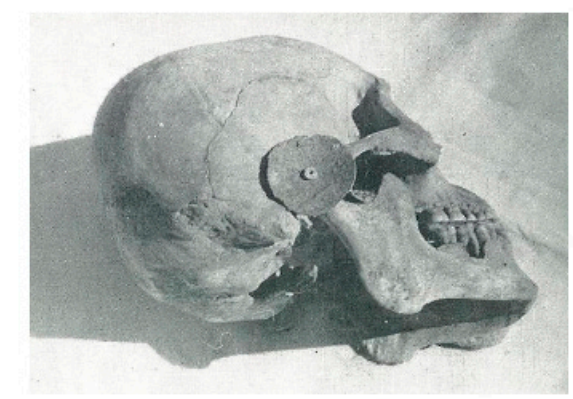

b)

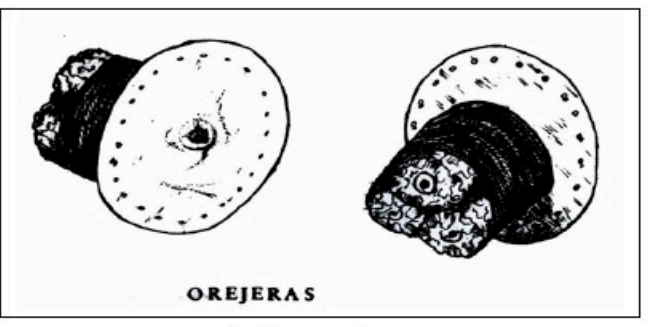

(Muñoz 1980:94)

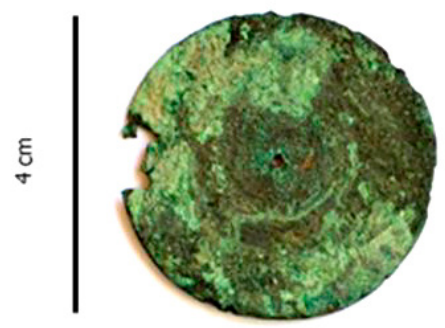

Figura 25. Orejera de la tumba 940 de Solor 3 (Fuente: Cifuentes 2014).

Figura 26. Orejeras in situ (San Pedro de Atacama) y orejeras completas (Arica). (Fuente: Cifuentes 2014). 
milares, formados por una lámina circular de plata unida a la base de tres zuros de maíz embarrilados con un hilo de lana. Están unidos por una ramita que tiene una cuenta de hueso, a modo de cabezal, ubicada en el centro de la lámina" (cita a Muñoz 1980). Este hallazgo es interpretado como una ofrenda Tiwanaku dispuesta en el borde del túmulo. Objetos similares son descritos en la cultura mochica (ca. 100 d. C. - 700 d. C.), representados en la cerámica como deformadores del lóbulo de la oreja (cita a Muñoz 1980), y en la cultura Vicús con diseños repujados y manufacturados en plata (cita a Ríos y Retamozo 1993)" (Cifuentes, 2014).

Tras observar las piezas descritas por Cifuentes y leer su reporte, pienso que es posible que algunas de las piezas consideradas por ella como orejeras, no sean tales (y tal vez sean pequeñas diademas para adherirse a los gorros, o lentejuelas para colocarse en los vestidos); pero también es posible que ocurra lo contrario, es decir que objetos considerados por nosotros como lentejuelas, hayan servido como colgantes para la oreja o aretes).

No podemos terminar el acápite, sin mencionar que pudo haber existido un tipo (variante) de adorno para la oreja, que no necesariamente requería la horadación del lóbulo, y que simplemente se colgaba del mismo a través de un pequeño hueco como sucede hoy con los llamados "aretes". El único caso posible (porque el hallazgo no proviene de una excavación controlada, y por tanto no se tiene ninguna clara señal) son dos piezas de oro encontradas junto a un conjunto mayor (hoy en el MMPP) en 1916 en la colina de la coronilla en Cochabamba, y que nosotros bautizamos como "El Tesoro de San Sebastián" (Sagárnaga 1988). Según recuerdo, en el orificio central superior, llevaban un alambre del mismo metal que, según mi conjetura, era el que se introducía en el lóbulo de la oreja para colgar el adorno. Presumo que todo el conjunto es de filiación tiwanaku.

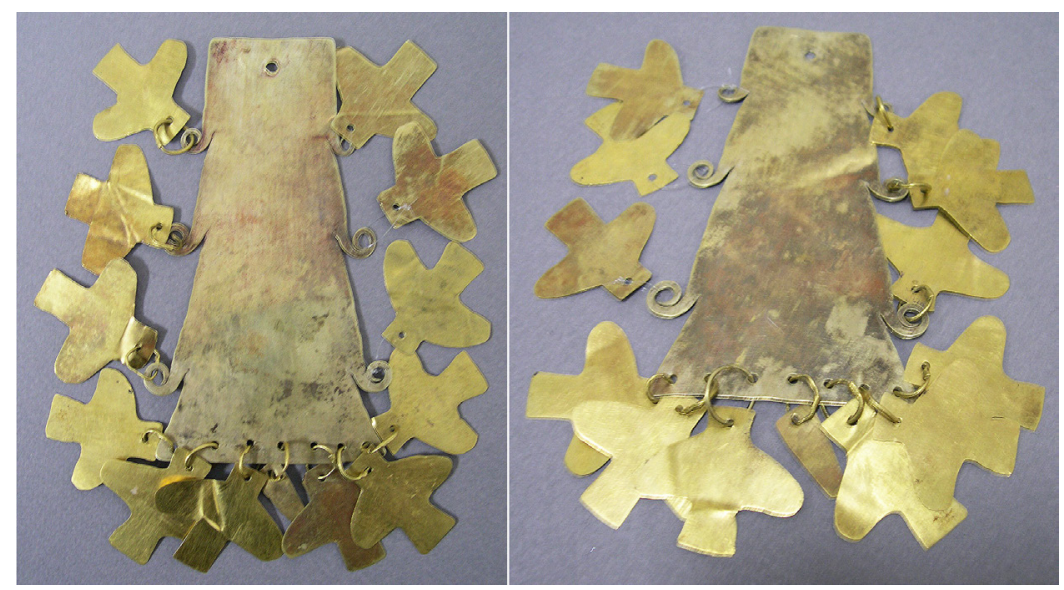

Figura 27. Par de "aretes" del "Tesoro de San Sebastián" (Fuente: Archivo MMPP). 


\section{¿Qué sucedía en Tierras Bajas?}

Es un hecho que el trabajo en metales no se desarrolló en el área que, gruesamente, podemos llamar chaco-amazónica, tema que profundizamos en otro artículo (Sagárnaga 2019). Pero son más o menos constantes los hallazgos de artefactos metálicos en distintos puntos de esa amplia zona geográfica, lo cual puede explicarse por el intercambio que se llevaba a cabo probablemente desde épocas más tempranas de las que suponemos.

Francisco de Orellana, el célebre capitán extremeño que en 1542 protagonizó una de las mayores gestas de la conquista de América, el haber atravesado de un extremo al otro el subcontinente sudamericano, desde Quito hasta la desembocadura del Amazonas en el Atlántico, se habría topado -según los relatos del cronista dominico fray Gaspar de Carvajal- con algunos indios que llevaban patenas de oro sobre el pecho, y sus mujeres se adornaban con ajorcas y orejeras de un inconfundible metal de color amarillo (HISTORIA National Geographic 2016).

Todavía hoy muchos pueblos indígenas de la Amazonia llevan orejeras aunque no precisamente de oro o algún metal. A guisa de ejemplo citemos a los chácobo, un pueblo de la familia de los Pano, con aproximadamente 500 miembros ubicados en el norte del departamento del Beni en la Amazonía boliviana En 1922 el etnólogo sueco Erland Nordenskiöld escribió que "pasada la pubertad, entre los 16 a 19 años, [a los niños] se les perforan los lóbulos de las orejas. Durante el proceso de curación se insertan trozos de madera, después se insertan colmillos de capibara. Para evitar perderlos, se sostienen en su lugar con cera" (Paniagua et al. 2017, p. 10). Añade que a las mujeres no se les perfora las orejas (Ibid, p. 11). Medio siglo después Marian Prost observó que los lóbulos de las orejas de los hombres "se perforan para poder insertar los dientes incisivos del capibara. De cada incisivo cuelga una sarta de cuentas de color celeste brillantes, que alcanza casi hasta la clavícula" (Ibid: 66). Similar cosa percibe Heinz Kelm cuando señala que "el chácobo de nuestros días lleva los mismos pendientes con dientes de Capibara en el agujero de oreja" (Ibid, p. 103).

Coincidentes los datos etnográficos del oriente, con los etnohistóricos de occidente, en cuanto al uso exclusivo de las orejeras por los hombres, y su empleo a partir de la pubertad.

En cuanto a lo que ocurría en la época prehispánica, conviene añadir acá un dato por demás relevante, pues tiene que ver con esta área, y es que en las excavaciones llevadas a cabo en la Loma Salvatierra en 2005 (Prümers y Jaimes, 2014, pp. 22-23), se hallaron los restos esqueletales de un individuo (tal vez un jerarca) que portaba a la altura de la frente una diadema circular de cobre y dos orejeras del mismo metal (figura 29). El dato es relevante no solo por la procedencia geográfica de los adornos, sino porque se trata de uno de los contados 

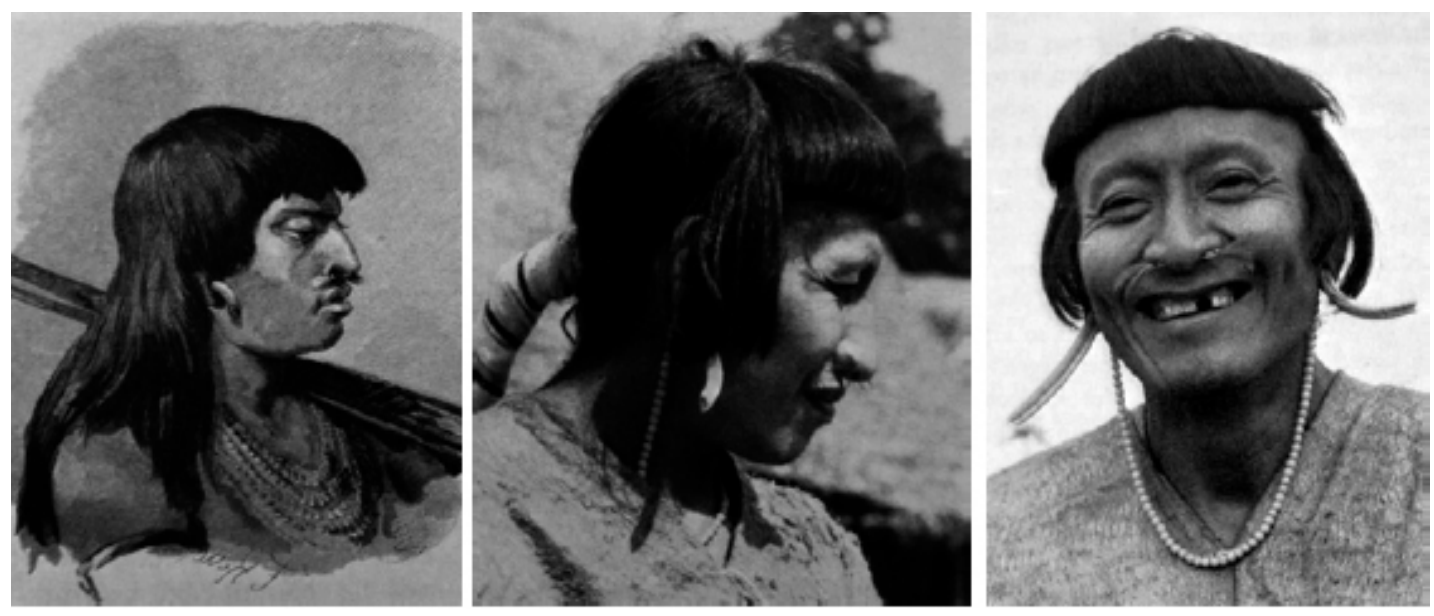

Figura 28. Rostros de hombres chácobo. En ellos se puede observar los adornos de nariz y orejas (según Kelm. Fuente: Paniagua et al.).

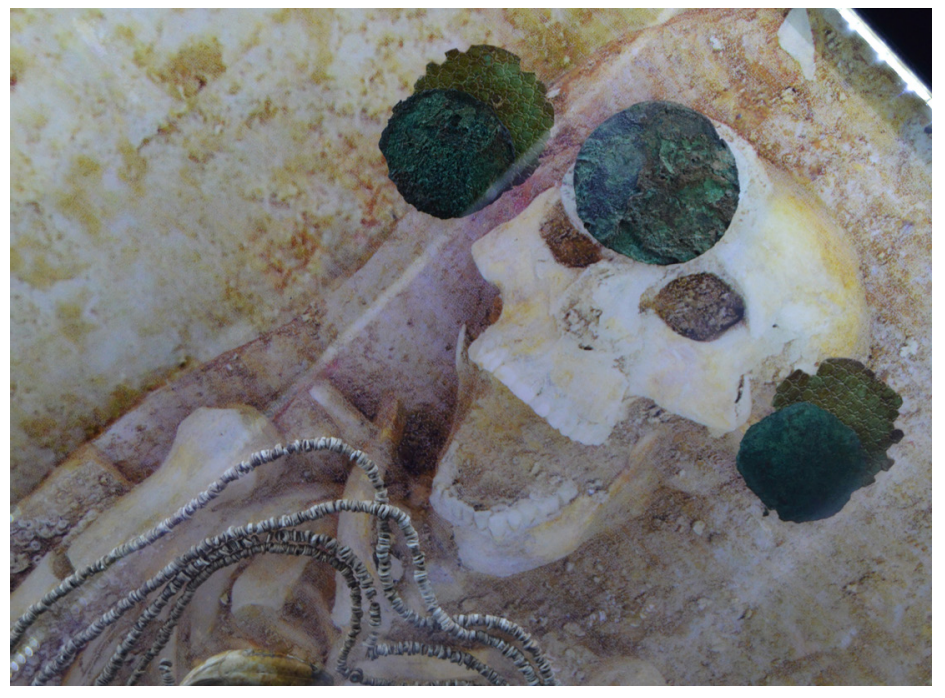

Figura 29. Individuo inhumado con un par de orejeras y una diadema circular, en la Loma Salvatierra (depto. del Beni) (Foto JASM, en el MUSEF).

hallazgos en excavación controlada. Lo más probable es que, como se tiene dicho, estos artefactos se hayan fabricado en Tierras Altas y llevado a las llanuras del Beni mediante intercambio.

Hay que anotar, de paso, que el uso de orejeras se mantuvo hasta época reciente entre grupos étnicos de las Tierras Bajas aunque no eran, precisamente, fabricadas en metal. 


\section{DISQUISICIONES}

La orejera en el Mundo Andino tuvo una notable importancia -según lo que puede colegirse del dato etnohistórico- como diferenciador de clases sociales y de grupos étnicos. También como diferenciador de género. Así mismo es probable que similar función hubiera cumplido en períodos anteriores.

En el Horizonte Tardío tuvo, además, importancia dentro del ámbito social toda vez que -como se ha señalado- fiestas y ceremonias importantes se realizaban para la horadación de los lóbulos y los individuos tomaban nombre nuevo en tales festividades.

El registro lexicográfico nos entrega términos como aron, pacu y tulumpi que se refieren a este tipo de adorno (Sagárnaga, 1989).

Consideramos que hay, al menos, tres variantes de adornos para las orejas: La primera cuyo cuerpo mismo se introduce en el lóbulo (normalmente discoidal); la que pende del lóbulo a través de algún artificio y la que tendría una espiga. Se detallan a continuación:

Variante "orejera". Aunque el término puede ser utilizado acá de manera muy arbitraria, con él nos referimos al adorno para orejas, que se encarna en el lóbulo. Se trata de una variante muy difundida en el tiempo. Vg. aparece representada en la cerámica tiwanaku (véanse figuras 12-18); se la ha encontrado en un contexto arqueológico mollo y también se la ubica en el registro arqueológico inka. Afecta forma de polea (o "carrete" como prefiere llamar Lothrop) y consta de dos placas circulares rígidas con una perforación circular más o menos grande en la parte central (véanse figs. 9-12). Ambas están unidas a un corto tubo cilíndrico mediante suelda. Todos los ejemplares que conocemos (alrededor de 10 pares) han sido elaborados invariablemente en oro, aunque no se descarta la posibilidad del empleo de otros metales en su confección. Su uso, aparentemente, traspasó las fronteras temporales, pues aparentemente se utilizó en el Horizonte Medio, en el Período Intermedio Tardío, y en el Horizonte Tardío.

Los objetos por nosotros estudiados pertenecen, sobre todo, a las colecciones CFDLP, CFBLP, CVM, MUSEF y PRTLP. Sabemos que la mayoría de los objetos de estas colecciones carecen de datos importantes como lugar de procedencia, y esto es lo que sucede con los objetos en cuestión.

Algo interesante de destacar es el hecho de haberse evidenciado la reutilización de estos objetos durante la época precolombina. Sucede que con el uso, sus partes se desprendían. Su propietario, entonces, martillaba la pieza y la perforaba en uno de sus extremos para reutilizarla como simple placa decorativa.

Las técnicas empleadas en su facturación fueron el laminado, el recortado y -como ya hemos dicho- la suelda. Las piezas que conocemos, no ostentan decoración repujada ni grabada. 
En el registro arqueológico Wari aparecen unas orejeras de metal con incrustaciones de piedras semipreciosas formando escenas diversas (véase, por ejemplo, Kauffmann, 1983, p. 461). Dada la similitud de artefactos wari y tiwanaku, no es improbable que los tiwanaku hubieran producido similares orejeras.

Variante "colgante". Otra variante de adorno para la oreja, es aquella que no precisa que los lóbulos se hallen tan dilatados ni con una gran perforación, y que bien podríamos llamar "arete". Los únicos ejemplares que conocemos proceden de Cochabamba y forman parte de lo que nosotros hemos llamado "El Tesoro de San Sebastián". Se trata de dos placas trapezoidales con una hilera de perforaciones en la parte de abajo y con tres volutas a cada costado de donde, mediante pequeños aros, se colgaban unas placas en forma de aves estilizadas. En la parte superior aparece una perforación traspasado por un hilo de oro que se introduciría, a su vez, en el lóbulo de la oreja (véase figura 25).

Variante con espiga. Una tercera variante tendría forma circular, sería más maciza y estaría adosada a una espiga, la cual se introduciría por el agujero del lóbulo de la oreja. Hasta ahora solo tenemos el dato iconográfico y un caso reportado en Arica (véanse figuras 19, 20, 21 y 24).

\section{Abreviaturas}

CFBLP Colección Fritz Buck

CFDLP Colección Federico Diez de Medina

CVM Colección Velasco Medina

IIAMInstituto de Investigaciones Arqueológicas y Museo R. P. Le Paige S. J. de la Universidad Católica del Norte

MBG Mónica Ballivián de Gutiérrez

MMPP Museo de Metales Preciosos Precolombinos, La Paz

MUNARQ Museo Nacional de Arqueología, La Paz

MUSEF Museo de Etnografía y Folklore, La Paz

PRTLP Colección de Pariti

JASM Jédu Antonio Sagárnaga Meneses

Agradecimientos: A los editores de la Revista ARQUEOLOGÍA Y SOCIEDAD, de la Universidad Nacional Mayor de San Marcos. A Eduardo Sagárnaga y Carola Condarco por haber leído el borrador y haber sugerido cambios. A Elizabeth Rocabado por haber provisto alguna bibliografía y a la estudiante Carmen Ramírez por haber hecho alguna contribución. También al o a los revisores ciegos encomendados por el IEB. 


\section{REFERENCIAS BIBLIOGRÁFICAS}

Acosta, J. de [1590] (1954). Historia natural y moral de las Indias. Biblioteca de Autores Españoles, tomo 73, pp. 3-247. Ediciones Atlas. Madrid.

Baudin, L. (1962). El Imperio Socialista de los Incas. Empresa Editora Zig Zag, S.A. Santiago de Chile.

Bingham, H. (1972). Machu Picchu. Empresa Editora Zig-Zag. Santiago de Chile.

Cobo, B. [1653] (1964). Historia del Nuevo Mundo. Biblioteca de Autores Españoles, tomos 91 y 92. Ediciones Atlas. Madrid.

Cifuentes A., A. (2014). Metales y Metalurgia en San Pedro de Atacama durante el Período Medio: hacia la definición de una metalurgia local. Memoria para optar al título profesional de arqueóloga. Universidad de Chile. Santiago.

Esquivias, A. (2014). El adorno humaniza. https://antoniovillalobos.wordpress. com/2014/12/30/el-adorno-humaniza/

Fernández, S. (2016). Alianzas de Metal La colección de minería y metales del Museo Nacional de Etnografía y Folklore, según la cadena de producción. Museo Nacional de Etnografía y Folklore. Fundación Cultural del Banco Central de Bolivia. La Paz.

Garcilaso de la Vega, El Inca [1609] (s/f). Comentarios reales de los Incas. Tres tomos. Editorial Universo S.A. Lima.

Gisbert, T. (1980). Iconografía y Mitos Indígenas en el Arte. Editores: Gisbert y Cia. S.A. La Paz. Guamán Poma de Ayala, F. [1580-1615] (1980). El Primer Nueva Corónica y Buen Gobierno. Edición Crítica de Murra, Adorno y Urioste. Primero de tres tomos. Colección América Nuestra. Siglo XXI Editores. México D.F.

Huidobro, J. (s/f). Informe de los objetos de oro de la Provincia Larecaja. Mecanuscrito. INAR. La Paz.

Huidobro, J. (1984). "Estudio arqueológico de la necrópolis de Palla Palla”, en Revista Andina 3 (Año 2 № 1, Julio), pp. 147-161. Centro Bartolomé de las Casas. Cusco.

Kauffmann Doig, F. (1983). Manual de Arqueología Peruana. Octava Edición. Ediciones PEISA. Lima.

Lothrop, S. K. (1937). Gold and Silver from Southern Peru and Bolivia, en The Journal of the Royal Anthropological Institute of Great Britain and Ireland. Vol. LXVII, julio a diciembre. Londres.

Medinaceli, X. (1995). Consultoría sobre Los Señoríos Aymara. MACB. Mecanuscrito. La Paz. 
Molina, C. de (El Chileno) [1553] (1968). Relación de muchas cosas acaescidas en el Perú. Biblioteca de Autores Españoles, tomo 209 (Crónicas Peruanas de Interés Indígena), pp. 57-95. Ediciones Atlas. Madrid.

National Geographic Historia (en español). (2016). La Exploración del Amazonas: La Gran Odisea de Francisco de Orellana. Octubre.

Paniagua, N.; R. Bussmann; C. Téllez y C Vega (eds.) (2017). La etnobotánica de los Chácobo en el siglo XX. Ethnobotany Research \& Applications.

Pizarro, P. [1571] (1978). Relación del descubrimiento y conquista del Perú. Pontificia Universidad Católica del Perú. Lima.

Posnansky, A. (1957). Tihuanacu: Cuna del Hombre Americano. (The Cradle of American Man). Tomos III y IV. Edición Bilingüe, Ingles-Castellano. Ministerio de Educación. Editorial Don Bosco. La Paz.

Prados Megías, M. E. (2002). La Construcción Cultural del Cuerpo. Tesis Doctoral, Departamento de Antropología y Trabajo Social. Universidad de Granada. Granada.

Prümers, H. y C. Jaimes (2014). 100 años de investigación arqueológica en los llanos de Mojos, en Arqueoantropológicas, 4(4). Publicación del INIAM-UMSS. Cochabamba.

Sagárnaga M., J. A. (1986 h). Orejeras andinas (1 $1^{a}$ parte). Matutino Presencia. La Paz, 29 de junio.

Sagárnaga M., J. A. (1986 i). Orejeras andinas (2ª parte). Matutino Presencia. La Paz, 24 de agosto.

Sagárnaga M., J. A. (1988). El Tesoro de San Sebastián, en revista Khrysos (Ciencia y Técnica del Oro), $\mathrm{N}^{\circ} 4$, pp. 52-57. La Paz.

Sagárnaga M.,J. A. (1989). Glosario de palabras andinas referidas al trabajo en metales. AVF Ediciones. La Paz, mayo.

Sagárnaga M., J. A. (1995). Metalistería Suntuaria Precolombina en el Altiplano Andino. (Su descripción y una aproximación a su análisis e interpretación). Tesis de grado para optar al grado de licenciatura en Arqueología. UMSA. Inédita.

Sagárnaga M., J. A. (2019). Consideraciones sobre el repertorio metálico prehispánico en las Tierras Bajas de Bolivia, en Textos Antropológicos, 20(1), 93-108. IIAA - Carrera de Antropología y Arqueología - Facultad Ciencias Sociales -UMSA. 


\section{SOBRE EL AUTOR}

\section{Jedu Sagárnaga}

Arqueólogo boliviano. Exdocente de las universidades Franz Tamayo, Aquino, UNIVALLE, San Francisco de Asís, UPEA y Católica. Docente titular en la Carreras de Arqueología e Historia (UMSA). Docente Investigador del Instituto de Investigaciones Arqueológicas y Antropológicas de la UMSA. Director de varios proyectos de investigación y de contrato desde 1996. Gerente de SCIENTIA Consultoría Cientifica. Autor de varios libros y opúsculos, además de un centenar de artículos. 